\title{
Pengaruh Corporate Governance Terhadap Penghindaran Pajak (Studi pada 7 Perusahaan Sektor Makanan dan Minuman di BEI 2015-2019
}

\author{
Cahyat Rohyana ${ }^{1}$, Diana Maryana ${ }^{2}$ \\ ${ }^{1,2}$ Politeknik Pos Indonesia \\ e-mail: ${ }^{1}$ cahyatrohyana@poltekpos.ac.id, ${ }^{2}$ dianamaryana@poltekpos.ac.id

\begin{tabular}{ccc}
\hline Diterima & Direvisi & Disetujui \\
$05-07-2021$ & $15-09-2021$ & $26-09-2021$ \\
\hline
\end{tabular}

\begin{abstract}
Abstrak - Pajak merupakan iuran wajib dibayarkan wajib pajak kepada negara. Wajib pajak yang dimaksud bisa berupa wajib pajak orang pribadi atau wajib pajak badan. Jika wajib pajak badan, maka pembayaran pajak dapat mengurangi perolehan laba. Guna mendaptakan laba yang besar, perusahaan dapat diindikasikan melakukan penghindaran pajak. Penghindaran pajak adalah salah satu bagian dari perencanaan pajak yang dilakukan secara legal. Salah satu hal untuk memperkecil penghindaran pajak dari pihak pengelola perusahaan dilakukan melalui Good Corporate Governance. Penelitian ini memiliki tujuan untuk mengetahui pengaruh dari kepemilikan institusional, dewan komisaris dan komite audit baik secara parsial maupun secara simultan terhadap penghindaran pajak. Hasil penelitian menunjukan terdapat pengaruh positif yang signifikan antara variabel kepemilikan institusional dengan variabel penghindaran pajak, terdapat pengaruh positif yang signifikan antara variabel dewan komisaris dengan variabel pengindaran pajak, tidak terdapat pengaruh yang signifikan antara variabel komite audit dengan variabel pengindaran pajak dan terdapat pengaruh positif yang signifikan antara kepemilikan institusional, dewan komisaris dan komite audit terhadap penghindaran pajak..
\end{abstract}

Kata Kunci: Pajak, Corporate Governance, Penghindaran Pajak

Abstract - Tax is a mandatory contribution paid by taxpayers to the state. The taxpayer in question can be an individual taxpayer or a corporate taxpayer. If the taxpayer is a corporate taxpayer, the payment of taxes can reduce profit. In order to get a large profit, the company can be indicated to do tax avoidance. Tax avoidance is one part of tax planning that is carried out legally. One of the things to minimize tax avoidance from the company management is through Good Corporate Governance. This study aims to determine the effect of institutional ownership, the board of commissioners and the audit committee either partially or simultaneously on tax avoidance. The results showed that there was a significant positive effect between the institutional ownership variable and the tax avoidance variable, there was a significant positive effect between the board of commissioners variable and the tax avoidance variable, there was no significant effect between the audit committee variable and the tax avoidance variable and there was a significant positive effect. between institutional ownership, board of commissioners and audit committee on tax avoidance.

Keywords: Tax, Corporate Governance, Tax Avoidance

\section{PENDAHULUAN}

Salah satu faktor penerimaan dari suatu negara adalah pajak, di mana pajak ini merupakan kontribusi kepada negara yang terutang oleh badan atau orang pribadi. Maka dari itu, pajak memiliki pengaruh yang sangat penting digunakan untuk pembiayaan negara maupun pembangunan nasional. Setiap negara mengupayakan mendapatkan penerimaan dari sektor pajak didalam kuantitas yang selayaknya berdasarkan potensi pajak yang mampu diperoleh dari tiap-tiap sektor usaha.

Usaha yang dilakukan pemerintah didalam optimalisasi penerimaan pajak di mulai dengan pergantian aturan perpajakan di tahun 2008 yang membuahkan revisi UU No. 36 tahun 2008 tentang penurunan tarif pajak. Direktur Eksekutif Pusat Studi Ekonomi dan Perpajakan (PSEP) mengatakan bahwa tax ratio perpajakan Indonesia terhadap tahun 2018 cuma sebesar $11,5 \%$, kebolehan pemerintah dalam menyatukan pajak dari total perkenomian atau dalam arti total produk domestik bruto cuma sebesar 11,5\%, di mana ini masih terbilang amat rendah dibanding tax ratio umumnya lower middle income country yang sebesar $17,7 \%$.

Tabel 1.1

Tax Ratio Indonesia 2015-2019

Capaian Tax Ratio Indonesia Tahun 2015-

2019

\begin{tabular}{|l|l|}
\hline 2015 & $11,6 \%$ \\
\hline 2016 & $10,8 \%$ \\
\hline
\end{tabular}




\begin{tabular}{|l|l|}
\hline 2017 & $10,7 \%$ \\
\hline 2018 & $11,5 \%$ \\
\hline 2019 & $11,9 \%$ \\
\hline
\end{tabular}

Tax Ratio Indonesia 2015-2019

(Sumber: www.kemenkeu.go.id)

Salah satu penyebab turunnya tax ratio Indonesia adalah adanya penghindaran atas pajak yang cukup marak dilakukan oleh wajib pajak, Direktur Jendral (Ditjen) Pajak Kementrian Keuangan Suryo Utomo menyatakan bahwa pada tahun 2020 terdapat temuan penghindaran pajak diperkirakan merugikan negara hingga Rp. 68,7 triliun pertahun. Nominal tersebut, sebanyak Rp. 67,6 triliun adalah penghindaran pajak yang berasal dari korporasi Indonesia dan Rp. 1,1 triliun yang berasal dari wajib pajak orang pribadi.

Menteri Keuangan menyebutkan penerimaan pajak di industri pengolahan atau manufaktur tahun 2019 sebesar Rp. 365,39 triliun. Angka tersebut menurun sebesar 1,8\% dibandingkan dengan realisasi penerimaan pajak disektor yang sama pada tahun 2018. Sektor makanan dan minuman adalah salah satu sektor yang berada didalam industri pengolahan atau manufaktur.

Penghindaran pajak adalah tidak benar satu bagian dari rencana pajak (tax planning) yang ditunaikan secara legal. Penghindaran pajak ini ditunaikan bersama maksud untuk mengurangi beban pajak. Penghindaran pajak merupakan hal yang istimewa, hal tesebut diperbolehkan namun punyai dampak, dimana mampu turunkan penerimaan negara.

Penghindaran pajak juga dapat dipengaruhi oleh tata kelola perusahaan atau yang dikenal dengan Corporate Governance. Menurut Sumihandayani (2013) dalam Ahmad dan Zulaikha (2015) menyatakan corporate governance merupakan suatu proses yang mengarahkan dan mengawasi suatu perusahaan, dalam praktiknya corporate governance memainkan lebih dari satu peran, diantaranya sebagai pengawas berasal dari penghindaran pajak, prosedur pengambilan ketetapan dan pemantauan kinerja agar dapat dipertanggungjawabkan. Corporate governance dibentuk untuk mengawasi tax planning agar dapat terjadi cocok dengan hukum yang berlaku. Coporate governace meyakinkan agar operasional perusahaan dalam perpajakan senantiasa berada dalam koridor penghindaran pajak yang legal agar tidak masuk kedalam koridor penghindaran pajak yeng berbentuk ilegal.

Kegiatan penghindaran pajak ini jadi hal perlu yang wajib diperhatikan oleh fiskus. Dalam riset ini penghindaran pajak diproksikan dengan rasio Effective Tax Rate (ETR), dalam Wardani, Anggra dan Amirah (2016: 7) ETR digunakan untuk menjelaskan presentase antara beban pajak penghasilan dibandingkan dengan laba perusahaan sebelum pajak. Pada penelitian Agung, Wilopo dan Yusri (2016) menunjukan bahwa corporate governance berpengaruh positif dan signifikan terhadap penghindaran pajak. Namun, pada penelitian Ahmad dan Zulaikha (2015) menunjukan bahwa corporate governance tidak berpengaruh signifikan terhadap penghindaran pajak. Perbedaan penelitian ini dibandingkan dengan penelitian sebelumnya yaitu variabel yang digunakan, dimana pada penelitian sebelumnya terdapat variabel kualitas audit, sedangkan didalam penelitian ini menggunakan variabel dewan komisaris.

\section{METODE PENELITIAN}

Metodologi penelitian yang dipakai oleh penulis yaitu metode pendekatan kuantitatif dengan memanfaatkan data sekunder yang di unduh dari situs www.idx.co.id maupun dari website resmi yang tersedia di perusahaan, diantaranya laporan tahunan perusahaan manufaktur sektor makanan \& minuman yang ada di Bursa Efek Indonesia (BEI) tahun 20152019.

\section{Populasi \& Sampel}

Populasi yang terdapat dalam penelitian di seluruh perusahaan manufaktur sektor makanan dan minuman, yang tercatat di Bursa Efek Indonesia pada tahun 2015-2019. Pengambilan sampel yang dipakai dalam penelitian ini yaitu dengan menggunakan metode purposive sampling dengan kriteria seperti dibawah ini :

1. Perusahaan manufaktur di BEI sektor food and bavearages (sebanyak51 Perusahaan)

2. Perusahaan manufaktur yang beroperasi di BEI sektor food and bavearages (sebanyak 26 Perusahaan)

3. Laporan keuangan lengkap 5 tahun (2015-2019).

4. Perusahaan yang menggunakan mata uang rupiah (Rp).

Setelah dilakukan penarikan sampel secara kriteria dan berdasarkan pertimbangan waktu, diperoleh perusahaan yang memenuhi standar sebanyak 7 perusahaan. Penelitian ini dilakukan selama periode pembukuan 2015-2019 sehingga jumlah sampel yang dipakai yaitu sebanyak 35 sampel.

\section{Persamaan dan simbol}

Variabel yang diteliti dalam penelitian ini adalah Kepemilikan Institusional (X1), Jumlah Dewan Komisaris (X2), Jumlah Komite Audit (X3) sebagai variabel independen yang mempengaruhi Penghindaran Pajak (Y) sebagai variabel dependen yang dipengaruhi.

\section{Teknik Analisis Data}

Teknik analisis data yang dipakai dalam penelitian yang dilakukan adalah metode analisis data kuantitatif meliputi Analisis Deksriptif, Uji Regresi Berganda, Uji Koefisien Determenasi \& Uji Hipotesis yang digunakan pada program SPSS (Statistic Package for Social Sciences) version 23 
sebagai alat untuk menguji data tersebut.

\section{HASIL DAN PEMBAHASAN}

\section{Statistik Deskriptif}

Menurut Sugiyono (2017:147) “Analisis deskriptif adalah metode yang digunakan untuk menggambarkan atau menganalisis suatu hasil penelitian tetapi tidak digunakan untuk membuat kesimpulan yang lebih luas". Penelitian ini menerapkan tiga variabel independen dan satu variabel dependen, hasilnya sebagai berikut:

\section{Tabel 4.1}

\begin{tabular}{|c|c|c|c|c|c|}
\hline Variabel & $\mathbf{N}$ & Min & Max & Mean & $\begin{array}{c}\text { Std. } \\
\text { Deviation }\end{array}$ \\
\hline X1 & 35 & 0.33 & 0.78 & 0.55630 & 0.11054 \\
\hline X2 & 35 & 0.33 & 0.50 & 0.36090 & 0.05669 \\
\hline X3 & 35 & 3.00 & 5.00 & 3.28570 & 0.71007 \\
\hline Y & 35 & 0.20 & 0.37 & 0.27660 & 0.04844 \\
\hline
\end{tabular}

(Sumber : Data Diolah Dengan Program SPSS)

Berdasarkan tabel 4.1 jumlah sampel yang menjadi dasar penelitian yaitu terdapat 35 sampel berdasarkan data dari laporan keuangan tahun 2015-2019, variabel penghindaran pajak (Y) memiliki nilai mean 0,2766 Nilai minimum sebesar 0,20 yang ada pada PT. Siantar Top Tbk tahun 2015 \& 2016. Sedangkan nilai maksimum sebesar 0,37 yang ada pada PT. Prashida Aneka Niaga pada tahun 2015. Standar deviasi sebesar 0,04844, hasil tersebut lebih kecil jika dibandingkan dengan nilai rata-rata.

Variabel Kepemilikan Institusional (X1) memiliki nilai mean 0,5563 . Dengan Nilai minimum 0,33 yang ada di PT. Mayora Indah Tbk tahun 2015. Sedangkan nilai maksimum 0,78 yang ada di PT. Prashida Aneka Niaga pada tahun 2016. Nilai standar deviasinya sebesar 0,11054 .

Pada variabel Dewan Komisaris Independen (X2) proporsi minimum sebesar 0,33 dan maksimum 0,50. Proporsi minimum yang ada di PT. Indofood Sukses Makmur Tbk yang terjadi di tahun 2015-2017. Selanjutnya, variabel Komite Audit (X3) proporsi minimum sebesar 3 dan maksimum 4 yang ada di PT. Mayora Indah Tbk.

\section{Analisis Koefisien Determenasi}

Tabel 4.2

Model Summary

\begin{tabular}{|l|c|r|r|r|}
\hline Model & $\mathrm{R}$ & $\begin{array}{c}\mathrm{R} \\
\text { Square }\end{array}$ & $\begin{array}{r}\text { Adjusted } \\
\text { R Square }\end{array}$ & $\begin{array}{c}\text { Std. Error of the } \\
\text { Estimate }\end{array}$ \\
\hline 1 & $.562^{\mathrm{a}}$ & .316 & .250 & .04195 \\
\hline
\end{tabular}

X1_KepemilikanInstitusional,

X2_DewanKomisarisIndependen

(Sumber : Data Diolah Dengan Program SPSS)
Berdasarkan tabel 4.2 diperoleh angka pada kolom R2 (R Square) sebesar 0,316 atau sebesar 31,6\% menunjukkan persentase pengaruh variabel independen (Kepemilikan Institusional, Dewan Komisaris Independen dan Komite Audit) berpengaruh terhadap variabel dependen (Effective Tax Rate) sebesar 31,6 \%, sedangkan 68,4 \% dipengaruhi oleh variabel lain yang tidak tergolong ke dalam model penelitian ini.

\section{Analisis Regresi Linier Berganda}

Persamaan regresi yang dihasilkan melalui uji analisis linear berganda (Tabel 4.3) sebagai berikut:

$\mathrm{Y}=0,092+0,196 \mathrm{X} 1+0,405 \mathrm{X} 2-0,021 \mathrm{X} 3$

Konstanta sebesar 0,092 menunjukkan bahwa jika variabel kepemilikan institusi (X1), dewan komisaris independen (X2), dan komite audit (X3) sama dengan nol, maka variabel penghindaran pajak (Y) tidak meningkat atau sama dengan 0,092 satuan.

Jika nilai variabel kepemilikan institusi (X1) bertambah 1, maka mengakibatkan nilai variabel penghindaran pajak (Y) akan bertambah senilai 0,196, karena koefisien regresi positif, maka akan terjadi hubungan positif antara kepemilikan institusi (X1) terhadap variabel penghindaran pajak (Y).

Jika nilai variabel komisaris independen (X2) bertambah 1, maka mengakibatkan nilai variabel penghindaran pajak (Y) akan bertambah senilai 0,405, karena koefisien regresi positif, sehingga terjadi hubungan positif antara komisaris independen (X2) terhadap variabel penghindaran pajak (Y). Jika nilai variabel komite audit (X3) bertambah 1, maka nilai variabel penghindaran pajak (Y) bertambah senilai $(0,021)$, karena koefisien regresi negatif, maka terjadi hubungan yang negatif antara komite audit (X3) terhadap variabel penghindaran pajak (Y).

\section{Uji t}

Berdasarkan hasil pengujian (uji t) pada tabel 4.3 diperoleh hasil sebagai berikut:

1. Terdapat pengaruh positif yang signifikan antara variabel kepemilikan institusional dengan variabel penghindaran pajak yang mempunyai nilai thitung 2,836>2,039 tabel dengan signifikasi $(0,008<0,05)$, maka Ho ditolak, maka disimpulkan bahwa kepemilikan institusional berpengaruh secara signifikan terhadap penghindaran pajak.

2. Terdapat pengaruh positif yang signifikan antara variabel dewan komisaris dengan variabel penghindaran pajak yang mempunyai nilai thitung $2,889>2,039$ tabel dengan signifikasi $(0,007<$ $0,05)$, maka Ho ditolak, maka disimpulkan bahwa dewan komisaris berpengaruh secara signifikan terhadap penghindaran pajak.

3. Tidak terdapat pengaruh positif yang signifikan antara variabel komite audit dengan variabel penghindaran pajak yang mempunyai nilai thitung $-2,032\langle 2,039$ tabel dengan signifikasi $(0,051\rangle$ $0,05)$. 


\section{Uji F}

Berdasarkan hasil Uji F dapat diketahui Fhitung sebesar 4,777 > Ftabel 3,30 dengan tingkat signifikasi $0,008<0,05$, artinya secara simultan variabel independent yang mencakup kepemilikan institusional (X1), dewan komisaris independent (X2), komite audit (X3) berpengaruh terhadap variabel penghindaran pajak $(\mathrm{Y})$

\section{Pembahasan}

Hasil penelitian menunjukan bahwa kepemilikan institusional berpengaruh positif dan signifikan pada penghindaran pajak. Yang dilakukan perusahaan guna mencapai keuntungan bottom line performance yang lebih tinggi serta menjamin investasi berkelanjutan, maka beban pajak perusahaan harus dikurangi melalu perencanaan pajak yang didorong oleh para pemilik institusional. Hasil penelitian ini bertolak belakang dengan penelitian yang dilakukan oleh Putri dan Herawati (2014) yang menyatakan bahwa kepemilikan institusional tidak berpengaruh terhadap penghindaran pajak. Tetapi, penelitian ini sejalan dengan penelitian yang dilakukan oleh Irwan dan Bambang (2018) yang menyatakan bahwa kepemilikan institusional berpengaruh positif dan signifikan terhadap penghindaran pajak.

Hasil penelitian menunjukan bahwa dewan komisaris berpengaruh positif dan vital terhadap penghindaran pajak. Proporsi dewan komisaris didalam perusahaan bisa menurunkan penghindaran pajak, supaya tambah tinggi dewan komisaris maka tambah baik kinerjanya didalam laksanakan pengawasan terhadap kinerja direksi atau manajemen didalam pengelolaan perusahaan. Hasil penelitian ini bersamaan dengan penelitian yang dikerjakan oleh Uun dan Puput (2016) yang tunjukkan bahwa dewan komisaris berpengaruh positif dan vital terhadap penghindaran pajak.

Hasil penelitian menunjukan bahwa komite audit tidak mempunyai efek positif dan signifikan pada penghindaran pajak. Secara teoritis, hasil penelitian ini sedikit tidak sama bersama dengan penelitian di awalnya yang dilaksanakan oleh Agung, Wilopo dan Yusri (2016) lebih-lebih pada efek komite audit pada penghindaran pajak. Pada penelitian ini komite audit tidak memiliki pengaruh positif dan signifikan terhadap penghindaran pajak. Dengan adanya perbedaan hasil dengan penelitian sebelumnya, membuktikan bahwa perbedaan jenis industri yang diteliti dapat mengakibatkan hasil penelitian yang berbeda.

\section{KESIMPULAN}

Ditinjau dari hasil penelitian terkait pengaruh corporate governance terhadap penghindaran pajak dengan instrument penelitian berupa data sekunder yaitu laporan keuangan tahunan periode 2015-2019 7 (tujuh) perusahaan manfukatur sector manakan dan minuman yang tergabung di bursa efek Indonesia (BEI), dan pembahasan yang dipaparkan, kesimpulannya sebagai berikut:

1. Terdapat pengaruh positif signifikan diantara variabel kepemilikan institusional dengan variabel penghindaran pajak.

2. Terdapat pengaruh positif signifikan diantara variabel dewan komisaris dengan variabel pengindaran pajak.

3. Tidak terdapat pengaruh positif signifikan diantara variabel komite audit dengan variabel pengindaran pajak.

4. Terdapat pengaruh positif signifikan diantara kepemilikan institusional, dewan komisaris dan komite audit terhadap penghindaran pajak.

\section{REFERENSI}

Sunarsih, Oktaviani. 2016. Good Corporate Governance in Manufacturing Companies Penghindaran pajak. Skripsi tidak diterbitkan. Jakarta. Sekolah Tinggi Ekonomi Indonesia.

Wardani, Anggara, Amirah. 2016. Pengaruh Karakteristik Perusahaan, Good Corporate Governance (GCG), dan Corporate Social Responsibility (CSR) Terhadap Penghindaran Pajak (Penghindaran pajak). Skripsi tidak diterbitkan. Bekasi. Universitas Pancasakti.

Novitasari, Nurhayati, Sukarmanto. 2015. Pengaruh Return on Asset, Leverage, Ukuran Komite Audit dan Kompetensi Komite Audit Terhadap Penghindaran pajak (Pada Perusahaan Jasa Sektor Property dan Real Estate di Bursa Efek Indonesia selama periode 2012-2014). Bandung. Universitas Islam Bandung.

Agung, Wilopo dan Yusri. (2016). Pengaruh Corporate Governance terhadap Penghindaran Pajak (Studi pada Perusahaan Terdaftar di Indeks Bursa Sri Kehati Tahun 2010-2014). Jurnal Perpajakan Vol. 11 No. 1. Kediri. Universitas Brawijaya.

Ahmad dan Zulaikha. (2015). Pengaruh Corporate Governance Terhadap Penghindaran Pajak (Studi Empiris pada Perusahaan Manufaktur yang Terdaftar di Bursa Efek Indonesia 20112014). Jurnal Akuntansi Vol. 4 No. 4. Semarang. Universitas Diponegoro.

Uun dan Puput. (2016). Pengaruh Corporate Governance Terhadap Penghindaran Pajak pada Perusahaan Manufaktur yang Terdafatar di Bursa Efek Indonesia. Jurnal Akuntansi Vol. 12 No. 2. Jakarta. Universitas Katolik Indonesia.

Luluk, Zahida. (2015). Analisis Tax Planning untuk Efisiensi Pajak Penghasilan. Jurnal Akuntansi. Malang. Universitas Kanjuruhan Malang.

Titiek dan Anni. (2016). Tren Penghindaran Pajak Perusahaan Manufaktur di Indonesia yang Terdafatar di BEI Tahun 2001-2014. Jurnal Akuntansi Vol. xx No. 3. Surakarta. Universitas Sebelas Maret.

Irwan dan Bambang. (2018). Pengaruh Kepemilikan Institusional, Kepemilikan Manajerial dan Proporsi Dewan Komisaris Independen Terhadap Tax Avoidance. Jurnal Akuntansi Vol. 20 No. 2. Purwokerto. Universitas Jenderal Soedirman.

Mardiasmo. 2016. Perpajakan - Edisi Terbaru 2016. Yogyakarta: Andi

Sugiyono. 2017. Metode Penelitian Kombinasi. Bandung : Alfabeta 
Sugiyono. 2016. Metode Penelitian Kuantitatif, Kualitatif dan R\&D. Bandung: Alfabeta

KNKG. (2006). Pedoman Umum Good Corporate Governance Indonesia. Komite Nasional Kebijakan Governance.

Kementrian Keuangan Republik Indonesia. 2019.
Mengejar Lompatan Rasio. Diunduh di https://www.kemenkeu.go.id/media/11884/med ia-keuangan-maret-2019.pdf 